\title{
Can the Ream and Run Procedure Improve Glenohumeral Relationships and Function for Shoulders With the Arthritic Triad?
}

\author{
Frederick A. Matsen III MD, Winston J. Warme MD, \\ Sarah E. Jackins PT
}

Received: 23 August 2014/Accepted: 2 December 2014/Published online: 9 December 2014

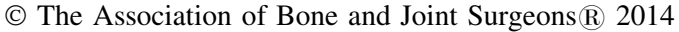

\begin{abstract}
Background The arthritic triad of glenoid biconcavity, glenoid retroversion, and posterior displacement of the humeral head on the glenoid is associated with an increased risk of failure of total shoulder joint replacement. Although a number of glenohumeral arthroplasty techniques are being used to manage this complex pathology, problems with glenoid component failure remain. In that the ream and run procedure manages arthritic pathoanatomy without a glenoid component, we sought evidence that this procedure can be effective in improving the centering of the humeral head contact on the glenoid and in improving the comfort and function of shoulders with the arthritic triad without the risk of glenoid component failure.
\end{abstract}

Each author certifies that he or she, or a member of his or her immediate family, has no funding or commercial associations (eg, consultancies, stock ownership, equity interest, patent/licensing arrangements, etc) that might pose a conflict of interest in connection with the submitted article.

All ICMJE Conflict of Interest Forms for authors and Clinical Orthopaedics and Related Research editors and board members are on file with the publication and can be viewed on request.

Each author certifies that his or her institution approved the human protocol for this investigation, that all investigations were conducted in conformity with ethical principles of research, and that informed consent for participation in the study was obtained.

F. A. Matsen III ( $₫)$, W. J. Warme

Department of Orthopedics and Sports Medicine, University of Washington Medical Center, Box 356500, 1959 NE Pacific St., Seattle, WA 98195, USA

e-mail: matsen@u.washington.edu

S. E. Jackins

University of Washington Exercise Training Center, Seattle, WA, USA
Questions/purposes We asked, for shoulders with the arthritic triad, whether the ream and run procedure could improve glenohumeral relationships as measured on standardized axillary radiographs and patient-reported shoulder comfort and function as recorded by the Simple Shoulder Test. Methods Between January 1, 2006 and December 14, 2011, we performed 531 primary anatomic glenohumeral arthroplasties for arthritis, of which 221 (42\%) were ream and run procedures. Of these, 30 shoulders in 30 patients had the ream and run procedure for the arthritic triad and had two years of clinical and radiographic follow-up. These 30 shoulders formed the basis for this case series. The average age of the patients was $56 \pm 8$ years; all but one were male. Two of the 30 patients requested revision to total shoulder arthroplasty within the first year after their ream and run procedure because of their dissatisfaction with their rehabilitation progress. For the 28 shoulders not having had a revision, we determined on the standardized axillary views before and after surgery the glenoid type, glenoid version $\left(90^{\circ}\right.$ minus the angle between the plane of the glenoid face and the plane of the body of the scapula), and location of the humeral contact point with respect to the anteroposterio dimension of the glenoid (the ratio of the distance from the anterior glenoid lip to the contact point divided by the distance between the anterior and posterior glenoid lips). We also recorded the patient's self-assessed shoulder comfort and function before and after surgery using the 12 questions of the Simple Shoulder Test.

Results For the 28 unrevised shoulders the mean followup was 3.0 years (range, 2-9.2 years). In these patients, the ream and run procedure resulted in improved centering of the humeral head on the face of the glenoid (preoperative: $75 \% \pm 7 \%$ posterior; postoperative: $59 \% \pm 10 \%$ posterior; mean difference $16 \%$ [95\% CI, 13\%-19\%]; $\mathrm{p}<0.001$ ), notably this improved centering was achieved 
without a significant change in the glenoid version. Patientreported function was improved (preoperative Simple Shoulder Test: $5 \pm 3$, postoperative Simple Shoulder Test: $10 \pm 4$, mean difference 5 [95\% CI, 4-6], $\mathrm{p}<0.001)$.

Conclusions In that ream and run is a new procedure, substantial additional clinical research with long-term follow-up is needed to define specifically the shoulder characteristics, the patient characteristics and the technical details that are most likely to lead to durable improvements in the comfort and function of shoulders with the challenging pathology known as the arthritic triad.

Level of Evidence Level IV, therapeutic study.

\section{Introduction}

\section{Background}

The clinical triad of glenoid biconcavity (erosion by the humeral head of a pathologic posterior glenoid concavity), retroversion (greater than $15^{\circ}$ posterior inclination of the plane of the glenoid with respect to the scapular body), and posterior subluxation of the humeral head on the glenoid face presents an important and unsolved clinical challenge for the glenohumeral arthroplasty surgeon. This type of arthritic pathoanatomy is commonly identified using plain axillary radiographs or CT scans, and accounts for as many as $40 \%$ of the osteoarthritic glenoids [2, 3, 5, 8, 10, 18, 20, $38,40,42,44,46,51]$.

Arthroplasty for shoulders with the arthritic triad is associated with an increased risk of glenoid component failure because of limited glenoid bone stock, difficulties in achieving secure glenoid fixation, posteriorly eccentric glenoid component loading and wear, and persistent posterior displacement of the humeral head with respect to the glenoid face $[1,3,6-8,10-12,14-17,19,21-24,30-37$, 41, 43, 48-50].

\section{Rationale}

The ream and run procedure [27] is a glenohumeral arthroplasty that combines a conventional humeral prosthesis with conservative concentric reaming of the glenoid bone without implanting a prosthetic anatomic or reverse glenoid component and without glenoid bone grafting. It has shown promising and durable results for treatment of glenohumeral arthritis $[9,26,28]$. We sought evidence that this procedure can be effective in treating shoulders with the arthritic triad, avoiding the risk of glenoid component failure.

We asked whether (1) the ream and run procedure could improve glenohumeral relationships as measured on standardized axillary radiographs, and (2) improve patient- reported shoulder comfort and function as recorded by the Simple Shoulder Test in shoulders with the arthritic triad.

\section{Methods}

In our practice, the ream and run procedure is offered to healthy individuals with glenohumeral osteoarthritis who wish to avoid the activity limitations and potential risks associated with an anatomic or reversed glenoid component, and who understand and embrace a rehabilitation program of multiple daily stretching sessions that may be more difficult and more protracted than the rehabilitation usually associated with a total shoulder arthroplasty. Patients considering the ream and run procedure receive extensive preoperative counseling regarding its pros and cons compared with the total shoulder arthroplasty, hemiarthroplasty, and reverse total shoulder arthroplasty for treatment of their shoulder disorder. The ream and run procedure is not offered to individuals receiving long-acting narcotic medication, those who are actively smoking, or with depression, inflammatory arthritis, complex posttraumatic anatomy, or psychosocial issues that, in the view of the surgeon, would compromise the chances of success. Patients with these relative contraindications are offered other treatment alternatives. Potential candidates are made aware of the factors associated with slower or less complete recovery from the ream and run procedure [9]. As a result, patients receiving the procedure are highly selected and not representative of the full breadth of patients and disorders needing shoulder arthroplasty.

Between January 1, 2006 and December 14, 2011, we performed 531 primary anatomic glenohumeral arthroplasties for glenohumeral arthritis, of which 221 (42\%) were ream and run procedures. The ream and run procedure was offered only to emotionally and physically healthy patients who understood the necessary dedication to a potentially challenging and long rehabilitation program and who wished to avoid the activity limitations generally imposed on shoulders with prosthetic glenoid components.

To be included in this case series, patients needed to have standardized pre- and postprocedure axillary radiographs taken with the arm elevated in the plane of the scapula (a position of function rather than with the arm at the side as is used for CT scans) and showing the spinoglenoid notch and enough of the scapular body to allow measurement of glenoid version (Fig. 1). Most of the patients who had the ream and run procedure lived a long distance away from our center and were unable to return to our clinic for the standardized postoperative radiographs 2 years after surgery. We attempted to obtain radiographs for these individuals from their local physicians; often, however, the necessary axillary views were either 


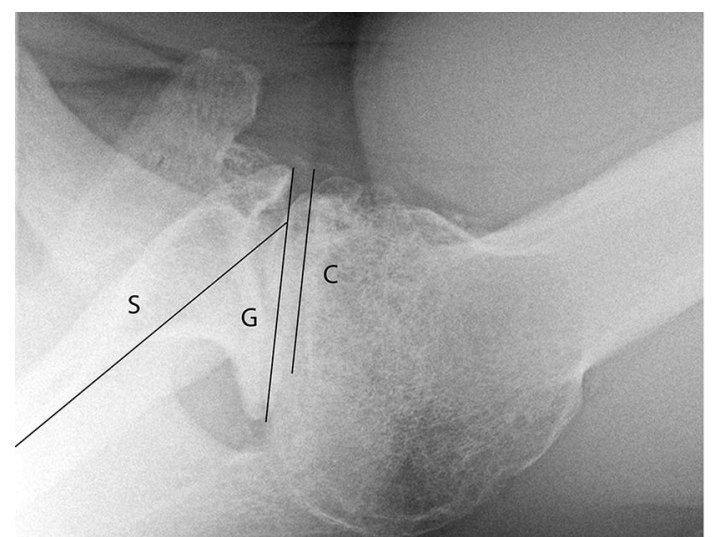

A

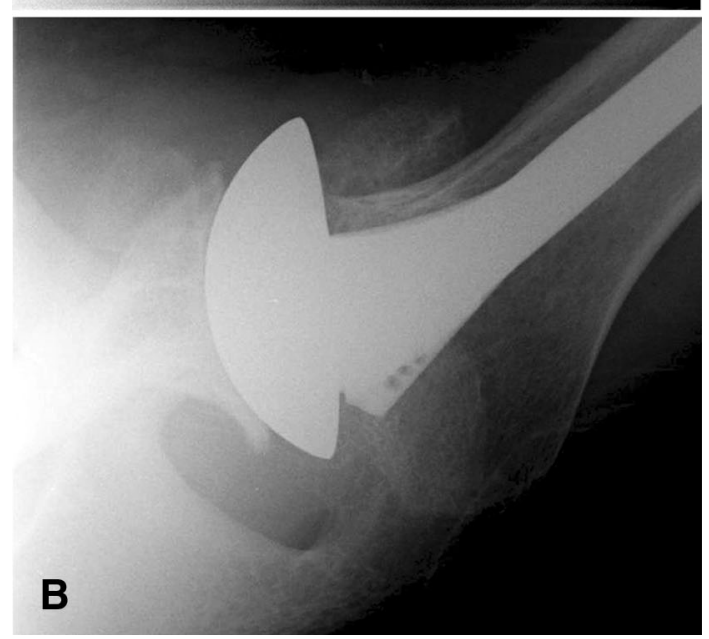

Fig. 1A-B A 50-year-old, left-handed man had the arthritic triad of his left shoulder. (A) His preoperative axillary view shows measurement of the glenoid angle (angle between lines S [plane of scapula] and $\mathrm{G}$ [plane of glenoid face]), and the relative position of humeral contact on the glenoid (ratio of the length of line segment $\mathrm{C}$ [from anterior lip of glenoid to center of point of contact] to that of line segment G [from anterior lip of glenoid to posterior lip of glenoid]). These measurements do not require normalization to the size of the humeral head or glenoid or determination of the center of the humeral head. (B) The patient's postoperative axillary view shows the use of an anteriorly eccentric humeral head component. Two years after the ream and run procedure, the patient sent a video showing himself doing handstand push-ups, pull-ups, bench pressing, passing a football, throwing a baseball, serving in tennis, and sinking three pointers on the basketball court.

unavailable or of insufficient quality to make the requisite measurements. As a result, only 60 of the shoulders having ream and run procedures during the study period had the standardized 2-year postoperative axillary radiographs necessary for inclusion. An analysis of the preoperative films of these 60 shoulders identified 30 shoulders in 30 patients with the arthritic triad (a pathologic glenoid concavity posterior to the normal anterior concavity, $15^{\circ}$ to $50^{\circ}$ glenoid retroversion, and posterior displacement of the humeral head contact point on the glenoid) before their ream and run procedure. These 30 shoulders formed the basis for this Level IV case series, recognizing that more shoulders would have been included had the necessary followup radiographs been available. The average age of the patients was $56( \pm 8)$ years and all but one were men. Twenty-three patients had primary osteoarthritis and seven had arthritis after a prior instability repair (capsulorrhaphy arthropathy). There were 17 right and 13 left shoulders.

Two of the 30 patients requested revision surgery to a total shoulder arthroplasty within the first postoperative year because of their dissatisfaction with their rehabilitation progress. For the 28 shoulders not having had revision surgery we determined on the standardized axillary views before and after surgery the glenoid type, glenoid version $\left(90^{\circ}\right.$ minus the angle between the plane of the glenoid face and the plane of the body of the scapula), and location of the humeral contact point on the glenoid with respect to the anteroposterior dimension of the glenoid (the ratio of the distance from the anterior glenoid lip to the contact point divided by the distance between the anterior and posterior glenoid lips) (Fig. 1). The importance of this contact point in shoulder arthroplasty has been reported [7, 45].

We also recorded the patient's self-assessed shoulder comfort and function before and after surgery using the 12 questions of the Simple Shoulder Test. The mean followup for these shoulders was 3.0 years (range, 2-9.2 years). Both shoulders that underwent early revision surgery had a preoperative diagnosis of arthritis after prior instability repairs and low preoperative Simple Shoulder Test scores (two of 12 functions). Both had the ream and run procedure in 2006, early during this case series. Because of the patients' dissatisfaction with their clinical improvement, both requested revision surgery to a total shoulder arthroplasty in less than a year after the ream and run procedure. They otherwise were not included in the analysis.

This was a new subgroup analysis that included patients from two prior studies. The first study presented the overall results of patients having ream and run surgery for arthritis between 2000 and 2008 [9], but the shoulders with arthritic triad were not analyzed separately. The second report concerned the pre- and postoperative radiographic findings in shoulders having the ream and run procedure between 2009 and 2013, including some with the arthritic triad, but the 2-year clinical outcomes of these procedures were not complete and thus were not included in the findings [26]. The current study is a previously unreported analysis of all 30 shoulders from the two groups that met the inclusion criteria of (1) having a ream and run procedure for treatment of the arthritic triad, confirmed by radiographs; and (2) having at least 2 years of followup or known surgical revision. 
All patients in this case series underwent primary ream and run shoulder arthroplasty by one of two surgeons (FAM and WJW) with extensive experience with the procedure. The details of the surgical technique have been reported, including the use of rotator interval plication and eccentric humeral heads to provide posterior stability [27]. In brief, the procedure included antibiotic prophylaxis with ceftriaxone and vancomycin, a double skin preparation with ChloraPrep ${ }^{\circledR}$ (CareFusion Corporation, San Diego, CA, USA), and a deltopectoral approach with incision of the subscapularis from the lesser tuberosity. Glenoid preparation included curettage of any remaining articular cartilage, burring of the ridge between the normal and posterior concavities, and conservative glenoid reaming just sufficient to convert the biconcavity into one concavity; there was no attempt to normalize glenoid version. As a result, the amount of glenoid bone removed was less than that removed for insertion of a glenoid component in a total shoulder arthroplasty; aggressive reaming was carefully avoided [49]. The diameter of curvature of the FDAapproved humeral head component (Global ${ }^{\circledR}$ Advantage ${ }^{\circledR}$, DePuy Orthopaedics, Inc, Warsaw, IN, USA) was chosen to be $2 \mathrm{~mm}$ less than that of the reamed glenoid; this small degree of mismatch has been used in all of our ream and run procedures; its purpose is to offer a small amount of humeral head translation without rim loading and to allow some room for growth of fibrocartilage on the surface of the reamed bone. Excessive posterior translation with the standard trial component in place (more than $50 \%$ of the head diameter on posterior loading of the proximal humerus) was managed with a 4-mm anteriorly eccentric humeral head [27]. The anteriorly eccentric humeral head did not appear to affect closure of the subscapularis. A rotator interval plication was used when there was excessive posterior translation after the definitive humeral component was in place; it consisted of four nonabsorbable sutures closing the interval between the upper border of the subscapularis tendon and the anterior border of the supraspinatus tendon. The procedure concluded with fixation of the humeral component using impaction grafting [4, 13], and subscapularis repair to the lesser tuberosity with six nonabsorbable sutures. The technique avoided a glenoid component, changing glenoid version, cement fixation, ingrowth humeral components, glenoid bone graft, interpositional allograft, and routine biceps tendon surgery. The humeral stem sizes used were $6 \mathrm{~mm}$ (1), $8 \mathrm{~mm}$ (one), $10 \mathrm{~mm} \mathrm{(10),} 12 \mathrm{~mm} \mathrm{(13),} \mathrm{and} 14 \mathrm{~mm}$ (five). Head diameters of the curvature were $44 \mathrm{~mm}$ (one), $48 \mathrm{~mm}$ (one), $52 \mathrm{~mm}$ (three), and $56 \mathrm{~mm}$ (25). Head heights were $15 \mathrm{~mm}$ (seven), $18 \mathrm{~mm}$ (seven), and $21 \mathrm{~mm}$ (16). Ten of the prostheses had humeral heads with an eccentric portion offset $4 \mathrm{~mm}$ anteriorly. Only one patient had biceps surgery, a tenodesis performed because of fraying of the tendon. Rotator interval plication was used in 11 cases. Posterior capsular plication was not used.

Continuous passive motion and active assisted forward elevation were initiated on the evening of surgery. Before discharge patients were instructed in and requested to perform assisted stretching using the supine stretch, pulley, and forward lean/table slide five times a day to achieve and maintain forward elevation of $150^{\circ}$ or greater. Six weeks after surgery, we introduced strengthening using the progressive supine press. We offered prescriptions for physical therapy to these individuals, but most preferred to do rehabilitation on their own, often sending us regular progress notes and photographs or videos of their ROM. Patients returned to their desired activities progressively as their comfort permitted. We imposed no limits on the patients' physical activities after 3 months.

Radiographic evaluation was performed immediately before surgery and at followup using standardized axillary views $[16,26]$. Patients unable to return to our center for followup were sent instructions specifying how the views were to be obtained, emphasizing the position of the arm in elevation in the plane of the scapula and the need to see the spinoglenoid notch and enough of the body of the scapula for measurement of glenoid version. Blinded to the clinical outcome, one of us (FAM) recorded glenoid shape $[26,46,47]$ and version, and the AP position of the point of humeral contact on the standardized radiographs (Fig. 1). The measurement methods have been shown to have a high degree of interobserver reliability and sensitivity to the changes effected by arthroplasty with a weighted $\kappa$ statistic of 0.86 for the agreement in glenoid type, Pearson correlation coefficient of 0.81 for the agreement in glenoid angle, and Pearson correlation coefficient of 0.92 for the AP location of the glenohumeral contact point [26].

Clinical results of our study were characterized by patient-reported outcomes obtained preoperatively and postoperatively using the Simple Shoulder Test, a shoulder-specific, observer-independent instrument that provides an overall score, along with the patient's reported ability to perform 12 individual shoulder functions. This outcome tool has been used extensively to evaluate the results of shoulder arthroplasty [9].

\section{Statistical Analysis}

Paired t-tests were used to characterize pre- and postoperative differences in glenoid version, the point of humeral contact on the glenoid, overall Simple Shoulder Test scores, and the ability to perform each of the 12 individual shoulder functions on the Simple Shoulder Test. The level of significance was p less than 0.05 . 
Table 1. Average ability of unrevised shoulders to perform each of 12 functions of the Simple Shoulder Test

\begin{tabular}{|c|c|c|c|c|}
\hline Individual function & $\begin{array}{l}\text { Able before } \\
\text { ream and run }\end{array}$ & $\begin{array}{l}\text { Able after } \\
\text { ream and run }\end{array}$ & Difference $(95 \% \mathrm{CI})$ & $\mathrm{p}$ (paired t test) \\
\hline Comfortable at rest & $64 \%$ & $96 \%$ & $32 \%(14 \%-50 \%)$ & 0.001 \\
\hline Sleep comfortably & $14 \%$ & $86 \%$ & $71 \%(54 \%-88 \%)$ & $<0.001$ \\
\hline Tuck in shirt behind & $39 \%$ & $86 \%$ & $46 \%(25 \%-67 \%)$ & $<0.001$ \\
\hline Place hand behind head & $43 \%$ & $82 \%$ & $39 \%(20 \%-58 \%)$ & $<0.001$ \\
\hline Place coin on high shelf & $57 \%$ & $96 \%$ & $39 \%(20 \%-58 \%)$ & $<0.001$ \\
\hline Lift 1 pound to shoulder level & $79 \%$ & $93 \%$ & $14 \%(-5 \%$ to $33 \%)$ & 0.161 \\
\hline Lift 8 pounds to shoulder level & $39 \%$ & $71 \%$ & $32 \%(12 \%-52 \%)$ & 0.004 \\
\hline Carry 20 pounds & $93 \%$ & $96 \%$ & $4 \%(-3 \%$ to $11 \%)$ & 0.326 \\
\hline Toss underhand & $43 \%$ & $89 \%$ & $46 \%(28 \%-65 \%)$ & $<0.001$ \\
\hline Throw overhand & $0 \%$ & $68 \%$ & $68 \%(5 \%-85 \%)$ & $<0.001$ \\
\hline Wash back of opposite shoulder & $11 \%$ & $64 \%$ & $54 \%(35 \%-72 \%)$ & $<0.001$ \\
\hline Do usual work & $64 \%$ & $86 \%$ & $21(3 \%-39 \%)$ & 0.031 \\
\hline
\end{tabular}

\section{Results}

Twenty-eight of the 30 shoulders were not revised after a mean followup of 3 years (range, 2-9.2 years). In these unrevised shoulders, the ream and run procedure resulted in improved centering of the humeral head on the face of the glenoid (preoperative: $75 \% \pm 7 \%$ posterior; postoperative: $59 \% \pm 10 \%$ posterior; mean difference $16 \%$ [95\% CI, $13 \%-19 \%$ ]; $\mathrm{p}<0.001)$. The improvements in humeral centering were achieved without a significant change in glenoid angle (preoperative: $60^{\circ} \pm 9^{\circ}$; postoperative: $63^{\circ} \pm 9^{\circ}$; mean difference $3^{\circ}[95 \% \mathrm{CI},-2$ to 8$], \mathrm{p}=0.22$ ).

Patient-reported function was improved (preoperative Simple Shoulder test: $5 \pm 3$, postoperative Simple Shoulder Test: $10 \pm 4$, mean difference 5 [95\% CI, 4-6], $\mathrm{p}<0.001)$. Ten of 12 individual shoulder functions of the Simple Shoulder Test improved (Table 1). As case examples of the application of this procedure to diverse clinical situations, the ream and run has been used to a severely deformed glenohumeral joint in a 50-year-old multisport athlete (Fig. 1), a severely biconcave glenoid in a 44-yearold baseball pitcher (Fig. 2), an irregular humeral head and pathologic posterior concavity in a 61-year-old violist (Fig. 3), and capsulorrhaphy arthropathy in a 35-year-old sailor (Fig. 4).

Two of the 30 shoulders underwent revision surgery before two years after surgery. Both had prior instability repairs (ie, a diagnosis of capsulorrhaphy arthropathy) and low preoperative Simple Shoulder Test scores (two of 12 functions). Their preoperative glenohumeral anatomy was not unusual among the 30 patients (contact points, $75 \%$ and $79 \%$ posterior; glenoid angles, $70^{\circ}$ and $58^{\circ}$ ). Because of the patients' dissatisfaction with the course of their recovery, both requested revision surgery to total shoulder arthroplasty in less than a year after the ream and run procedure. Their prerevision radiographs revealed no apparent mechanical problems. These two patients otherwise were not included in the analysis. There were no other revision procedures. There were no surgical or medical complications and no cases of posterior instability.

\section{Discussion}

The glenohumeral arthritic triad (glenoid biconcavity, glenoid retroversion, and posterior displacement of the humeral head on the face of the glenoid) poses a major challenge in shoulder reconstruction. It is associated with an increased rate of failure with conventional total shoulder arthroplasty [25, 49], causing surgeons to consider more complex and potentially more risk-prone options, such as posterior glenoid bone grafting to add support to the prosthetic glenoid component [39] or reverse total shoulder arthroplasty [29]. The ream and run is a glenohumeral arthroplasty that combines humeral hemiarthroplasty with conservative glenoid reaming just sufficient to convert the biconcavity to a single concavity, but without attempting to normalize glenoid version and without insertion of a prosthetic glenoid component. Because the version is not normalized and there are no holes for glenoid component fixation, less bone is removed with a ream and run procedure than to prepare the glenoid for a prosthesis. If necessary, posterior stability is augmented through the use of anteriorly offset humeral head components and rotator interval plication. Because the arthritic triad commonly affects younger, more active individuals (the average age of our patients was $56 \pm 8$ years), the ream and run procedure can be attractive because it eliminates the lifetime risk of glenoid component failure. The aims of the current case series were to determine, in selected 


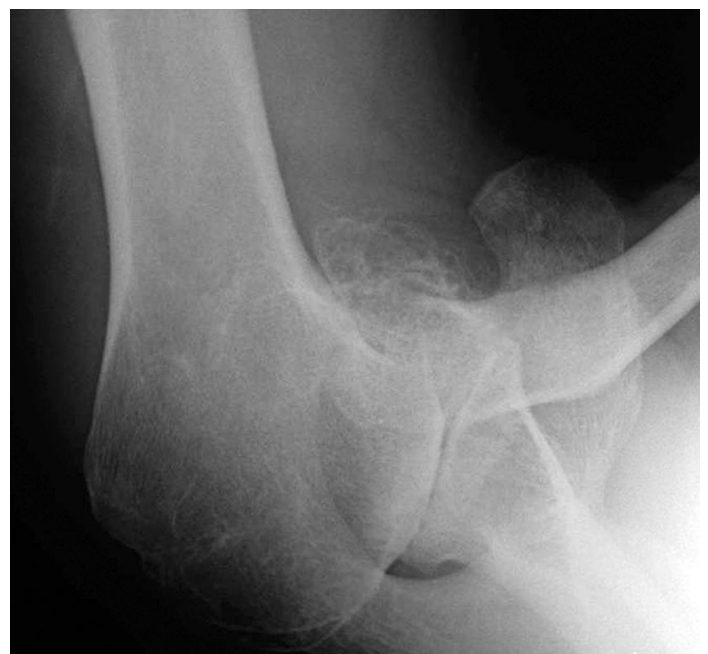

A

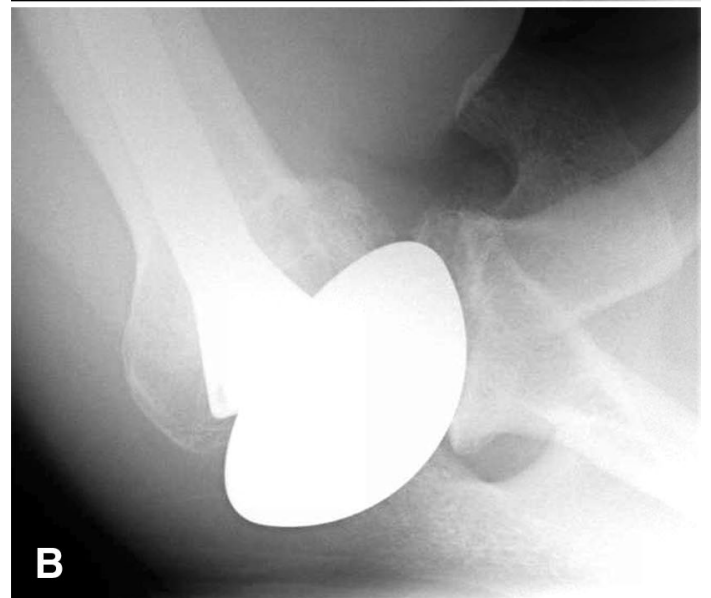

Fig. 2A-B A 44-year-old, right-handed man had the arthritic triad of the right shoulder. (A) His preoperative axillary view shows a severely biconcave glenoid and posterior displacement of the humeral contact point on the glenoid. (B) The postoperative axillary view shows a single glenoid concavity and improved humeral head centering on the glenoid; an anteriorly eccentric humeral head was used. Three years after the patient's ream and run procedure, he sent a video of himself throwing at batting practice (for 1 hour, 35 minutes; 200-300 pitches). He also has completed the Tough Mudder competition since his surgery.

patients with the arthritic triad, (1) if the ream and run procedure improves glenohumeral articular relationships as measured on standard axillary radiographs, and (2) if the ream and run procedure improves patient-reported shoulder comfort and function as recorded by the Simple Shoulder Test.

This study has some limitations. First, when applied to shoulders with the arthritic triad, the ream and run procedure is a technically demanding procedure with a substantial learning curve; as a result, it may not be attractive to many surgeons. Second, the ream and run procedure may not be appropriate for many patients, such
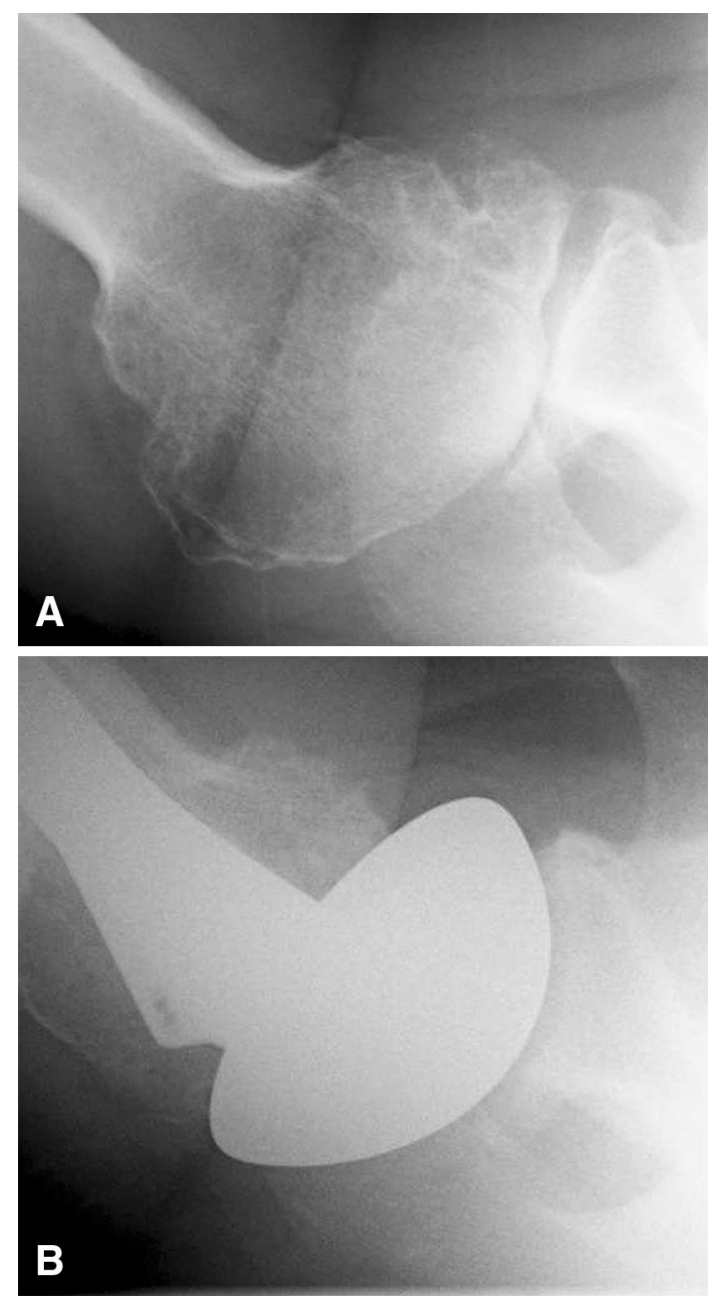

Fig. 3A-B A 61-year-old concert violist with the arthritic triad of his right (bowing) shoulder returned to performing within 1 year after his ream and run procedure. (A) The preoperative axillary view shows an irregular humeral head articulating with a pathologic posterior concavity. (B) The postoperative axillary view shows an anteriorly eccentric humeral head component centered on the reamed glenoid fossa.

as patients with low activity expectations, poor health, or reluctance to commit to the necessary rehabilitation program. Thus our study results may not be generalizable to other groups of patients or other surgeons. Third, because of the requirement for obtaining axillary view radiographs 2 years postoperative, taken with the arm elevated in the scapular plane, and showing the spinoglenoid notch and enough of the body of the scapular body to enable measurement of glenoid version, a substantial number of patients having the ream and run procedure could not be considered for inclusion in this study. Fourth, the opportunity to compare the results of our series with results of others that used alternative methods to treat the arthritic triad is compromised by differences in patient age, patient sex, glenohumeral pathoanatomy, and the methods of 


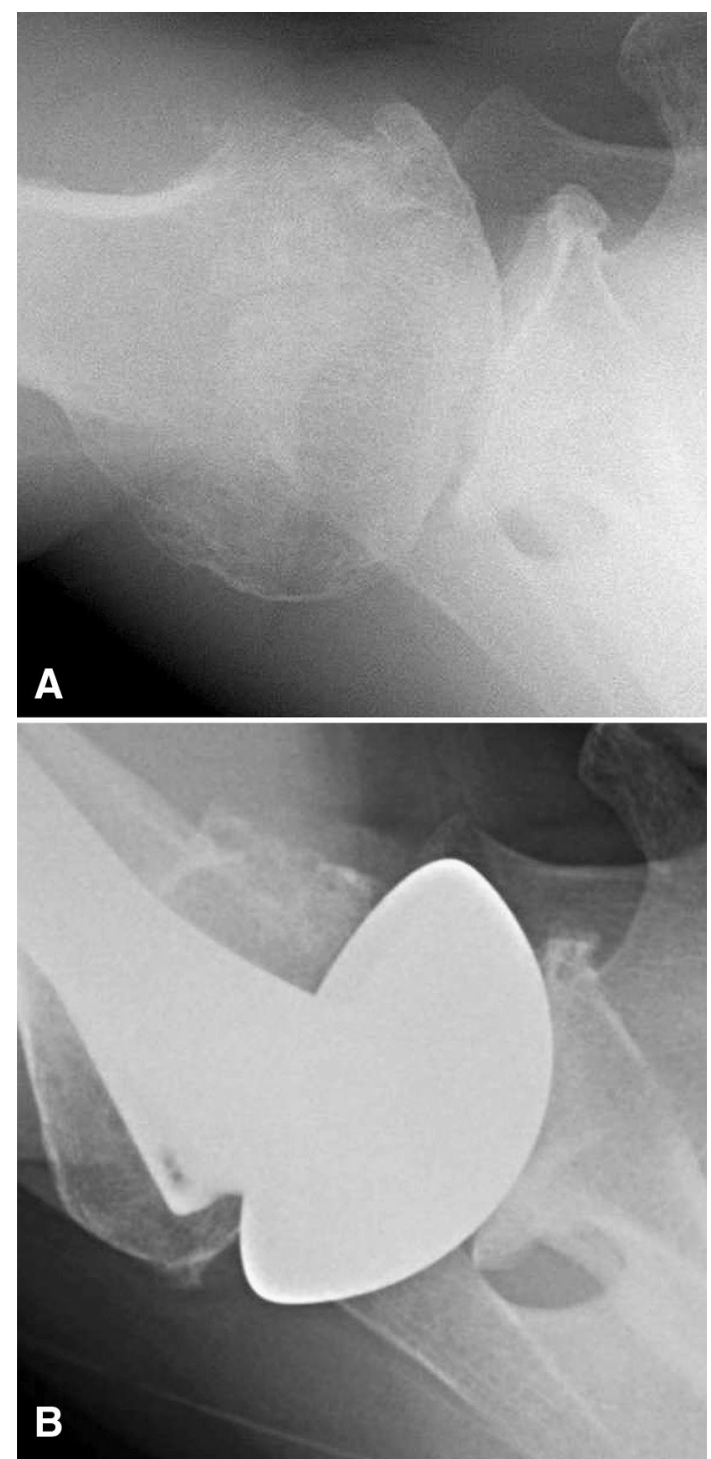

Fig. 4A-B A 35-year-old sailor returned to competition within a year of his ream and run procedure for the arthritic triad. (A) His preoperative axillary view shows the arthritic triad after a prior repair for anterior instability. (B) The postoperative axillary view shows centering in the reamed glenoid of an anteriorly eccentric humeral head component.

clinical and radiographic assessment. For example, taking the axillary radiograph with the arm in a functional position of elevation may yield a different amount of posterior displacement of the humeral head on the glenoid than what might be seen with a CT scan with the arm resting at the patient's side [45]. Fifth, although we report the use of eccentric humeral heads and rotator interval plication to stabilize the humeral head on the glenoid, we have not rigorously documented the effectiveness of these techniques. Sixth, our study met the often-used criterion of a minimum 2-year followup, however, it does not provide long-term followup data to assure the absence of delayed glenoid erosion or bony glenoid failure. However, Mercer et al. [28] reported that medial migration of the humeral head after a ream and run procedure was less than $0.4 \mathrm{~mm}$ per year.

We found that the ream and run procedure can improve centering of the humeral head on the glenoid in shoulders with the arthritic triad without altering glenoid version and with preservation of glenoid bone stock. This finding is important because some surgeons believe that normalizing glenoid version is necessary to achieve posterior stability, leading them to consider bone grafting under the posterior aspect of the glenoid component [39]. Other surgeons are using the reverse total shoulder arthroplasty as a method for stabilizing the glenohumeral joint in shoulders with the arthritic triad [29]. It is apparent that each of these methods may be useful for treatment of various glenohumeral disorders in different shoulders.

We also found that patient-reported shoulder comfort and function can be improved at 2 years after the ream and run procedure. Improvements were particularly remarkable in the comfort of the shoulder at rest, the ability to sleep comfortably, to tuck in a shirt, to wash the back of the opposite shoulder, to place the hand behind the head, to lift forward, to toss underhand, and to throw overhand. As shown in the case examples, some of the individuals included in our study were able to achieve extraordinary levels of physical function after the ream and run procedure. Documentation of the change in individual shoulder functions allows for a meaningful conversation with prospective patients regarding the outcomes that might be anticipated after surgery.

The two patients electing to have their ream and run procedures revised to total shoulder arthroplasties within the first year postoperative had the ream and run procedures performed in 2006, early during our series, before we fully understood the importance of preoperative counseling regarding this procedure. There were no obvious differences between these shoulders and others in the series. It is possible that with better preoperative counseling these revisions could have been avoided, either if the patients would have selected another treatment option or if they had been encouraged to pursue rehabilitation longer or more vigorously.

The ream and run is a procedure that is being progressively refined, in terms of defining the shoulder disorders and the patients who might be best served by it, and the technique of the procedure. Its attractive features include removal of a minimal amount of glenoid bone, avoidance of the risks and activity limitations associated with a prosthetic glenoid component, and the opportunity to improve humeral centering on the glenoid without removing or adding bone in an attempt to change glenoid version. This Level IV case series showed that the ream and run procedure can be clinically effective in shoulders 
with one of the most challenging glenohumeral disorders: the arthritic triad. Substantial additional research is needed to refine patient selection and surgical technique so that the role of this procedure in the treatment of different shoulder arthropathies can be better clarified.

\section{References}

1. Antuna SA, Sperling JW, Cofield RH, Rowland CM. Glenoid revision surgery after total shoulder arthroplasty. J Shoulder Elbow Surg. 2001;10:217-224.

2. Beuckelaers E, Jacxsens M, Van Tongel A, De Wilde LF. Threedimensional computed tomography scan evaluation of the pattern of erosion in type B glenoids. J Shoulder Elbow Surg. 2014; 23:109-116.

3. Boileau P, Avidor C, Krishnan SG, Walch G, Kempf JF, Mole D. Cemented polyethylene versus uncemented metal-backed glenoid components in total shoulder arthroplasty: a prospective, doubleblind, randomized study. J Shoulder Elbow Surg. 2002;11:351359.

4. Boorman RS, Hacker SA, Lippitt SB, Matsen FA 3rd. A conservative broaching and impaction grafting technique for humeral component placement and fixation in shoulder arthroplasty: the procrustean method. Tech Shoulder Elbow Surg. 2001;2:166175.

5. Collin P, Tay AK, Melis B, Boileau P, Walch G. A ten-year radiologic comparison of two-all polyethylene glenoid component designs: a prospective trial. J Shoulder Elbow Surg. 2011;20:1217-1223.

6. Edwards TB, Boulahia A, Kempf JF, Boileau P, Nemoz C, Walch G. Shoulder arthroplasty in patients with osteoarthritis and dysplastic glenoid morphology. J Shoulder Elbow Surg. 2004;13:1-4.

7. Farron A, Terrier A, Buchler P. Risks of loosening of a prosthetic glenoid implanted in retroversion. J Shoulder Elbow Surg. 2006;15:521-526.

8. Gerber C, Costouros JG, Sukthankar A, Fucentese SF. Static posterior humeral head subluxation and total shoulder arthroplasty. J Shoulder Elbow Surg. 2009;18:505-510.

9. Gilmer BB, Comstock BA, Jette JL, Warme WJ, Jackins SE, Matsen FA. The prognosis for improvement in comfort and function after the ream-and-run arthroplasty for glenohumeral arthritis: an analysis of 176 consecutive cases. J Bone Joint Surg Am. 2012;94:e102.

10. Godeneche A, Boileau P, Favard L, Le Huec JC, Levigne C, Nove-Josserand L, Walch G, Edwards TB. Prosthetic replacement in the treatment of osteoarthritis of the shoulder: early results of 268 cases. J Shoulder Elbow Surg. 2002;11: $11-18$.

11. Greiner S, Berth A, Kaab M, Irlenbusch U. Glenoid morphology affects the incidence of radiolucent lines around cemented pegged polyethylene glenoid components. Arch Orthop Trauma Surg. 2013;133:1331-1339.

12. Habermeyer P, Magosch P, Luz V, Lichtenberg S. Threedimensional glenoid deformity in patients with osteoarthritis: a radiographic analysis. J Bone Joint Surg Am. 2006;88:13011307.

13. Hacker SA, Boorman RS, Lippitt SB, Matsen FA 3rd. Impaction grafting improves the fit of uncemented humeral arthroplasty. J. Shoulder Elbow Surg. 2003;12:431-435.

14. Hawkins RJ, Greis PE, Bonutti PM. Treatment of symptomatic glenoid loosening following unconstrained shoulder arthroplasty. Orthopedics. 1999;22:229-234.
15. Hill JM, Norris TR. Long-term results of total shoulder arthroplasty following bone-grafting of the glenoid. J Bone Joint Surg Am. 2001;83:877-883.

16. Ho JC, Youderian A, Davidson IU, Bryan J, Iannotti JP. Accuracy and reliability of postoperative radiographic measurements of glenoid anatomy and relationships in patients with total shoulder arthroplasty. J Shoulder Elbow Surg. 2013;22:10681077.

17. Hopkins AR, Hansen UN, Amis AA, Emery R. The effects of glenoid component alignment variations on cement mantle stresses in total shoulder arthroplasty. J Shoulder Elbow Surg. 2004;13:668-675.

18. Hsu JE, Ricchetti ET, Huffman GR, Iannotti JP, Glaser DL. Addressing glenoid bone deficiency and asymmetric posterior erosion in shoulder arthroplasty. J Shoulder Elbow Surg. 2013;22:1298-1308.

19. Iannotti JP, Norris TR. Influence of preoperative factors on outcome of shoulder arthroplasty for glenohumeral osteoarthritis. J Bone Joint Surg Am. 2003;85:251-258.

20. Kany J, Katz D. How to deal with glenoid type B2 or C? How to prevent mistakes in implantation of glenoid component? Eur J Orthop Surg Traumatol. 2013;23:379-385.

21. Keller J, Bak S, Bigliani LU, Levine WN. Glenoid replacement in total shoulder arthroplasty. Orthopedics. 2006;29:221-226.

22. Kircher J, Wiedemann M, Magosch P, Lichtenberg S, Habermeyer P. Improved accuracy of glenoid positioning in total shoulder arthroplasty with intraoperative navigation: a prospective-randomized clinical study. J Shoulder Elbow Surg. 2009;18: $515-520$.

23. Kontakis GM, Tozakidou M, Karantinos J. Stabilisation of a posteriorly unstable glenohumeral joint during total shoulder arthroplasty: a novel capsulorrhaphy technique. Acta Orthop Belg. 2006;72:353-355.

24. Levine WN, Djurasovic M, Glasson JM, Pollock RG, Flatow EL, Bigliani LU. Hemiarthroplasty for glenohumeral osteoarthritis: results correlated to degree of glenoid wear. J Shoulder Elbow Surg. 1997;6:449-454.

25. Matsen FA 3rd, Clinton J, Lynch J, Bertelsen A, Richardson ML. Glenoid component failure in total shoulder arthroplasty. $J$ Bone Joint Surg Am. 2008;90:885-896.

26. Matsen FA 3rd, Gupta A. Axillary view: arthritic glenohumeral anatomy and changes after ream and run. Clin Orthop Relat Res. 2014;472:894-902.

27. Matsen FA 3rd, Lippitt SB. Current technique for the ream-andrun arthroplasty for glenohumeral osteoarthritis. JBJS Essent Surg Techn. 2012;2:e20, 21-15.

28. Mercer DM, Gilmer BB, Saltzman MD, Bertelsen A, Warme WJ, Matsen FA 3rd. A quantitative method for determining medial migration of the humeral head after shoulder arthroplasty: preliminary results in assessing glenoid wear at a minimum of two years after hemiarthroplasty with concentric glenoid reaming. J. Shoulder Elbow Surg. 2011;20:301-307.

29. Mizuno N, Denard PJ, Raiss P, Walch G. Reverse total shoulder arthroplasty for primary glenohumeral osteoarthritis in patients with a biconcave glenoid. J Bone Joint Surg Am. 2013;95:12971304.

30. Moeckel BH, Altchek DW, Warren RF, Wickiewicz TL, Dines DM. Instability of the shoulder after arthroplasty. $J$ Bone Joint Surg Am. 1993;75:492-497.

31. Namba RS, Thornhill TS. Posterior capsulorrhaphy in total shoulder arthroplasty: a case report. Clin Orthop Relat Res. 1995;313:135-139.

32. Neer CS 2nd, Morrison DS. Glenoid bone-grafting in total shoulder arthroplasty. J Bone Joint Surg Am. 1988;70:11541162. 
33. Neyton L, Walch G, Nove-Josserand L, Edwards TB. Glenoid corticocancellous bone grafting after glenoid component removal in the treatment of glenoid loosening. J Shoulder Elbow Surg. 2006;15:173-179.

34. Norris TR, Iannotti JP. Functional outcome after shoulder arthroplasty for primary osteoarthritis: a multicenter study. J Shoulder Elbow Surg. 2002;11:130-135.

35. Nowak DD, Bahu MJ, Gardner TR, Dyrszka MD, Levine WN, Bigliani LU, Ahmad CS. Simulation of surgical glenoid resurfacing using three-dimensional computed tomography of the arthritic glenohumeral joint: the amount of glenoid retroversion that can be corrected. J Shoulder Elbow Surg. 2009;18: 680-688.

36. Nyffeler RW, Sheikh R, Atkinson TS, Jacob HA, Favre P, Gerber C. Effects of glenoid component version on humeral head displacement and joint reaction forces: an experimental study. J Shoulder Elbow Surg. 2006;15:625-629.

37. Orfaly RM, Rockwood CA Jr, Esenyel CZ, Wirth MA. A prospective functional outcome study of shoulder arthroplasty for osteoarthritis with an intact rotator cuff. J Shoulder Elbow Surg. 2003;12:214-221.

38. Rouleau DM, Kidder JF, Pons-Villanueva J, Dynamidis S, Defranco M, Walch G. Glenoid version: how to measure it? Validity of different methods in two-dimensional computed tomography scans. J Shoulder Elbow Surg. 2010;19:1230-1237.

39. Sabesan V, Callanan M, Ho J, Iannotti JP. Clinical and radiographic outcomes of total shoulder arthroplasty with bone graft for osteoarthritis with severe glenoid bone loss. J Bone Joint Surg Am. 2013;95:1290-1296.

40. Scalise JJ, Codsi MJ, Brems JJ, Iannotti JP. Inter-rater reliability of an arthritic glenoid morphology classification system. J Shoulder Elbow Surg. 2008;17:575-577.

41. Scalise JJ, Iannotti JP. Bone grafting severe glenoid defects in revision shoulder arthroplasty. Clin Orthop Relat Res. 2008;466: 139-145.
42. Sears BW, Johnston PS, Ramsey ML, Williams GR. Glenoid bone loss in primary total shoulder arthroplasty: evaluation and management. J Am Acad Orthop Surg. 2012;20:604-613.

43. Shapiro TA, McGarry MH, Gupta R, Lee YS, Lee TQ. Biomechanical effects of glenoid retroversion in total shoulder arthroplasty. J Shoulder Elbow Surg. 2007;16(3 suppl):S90-95.

44. Szabo I, Buscayret F, Edwards TB, Nemoz C, Boileau P, Walch G. Radiographic comparison of flat-back and convex-back glenoid components in total shoulder arthroplasty. J Shoulder Elbow Surg. 2005;14:636-642.

45. von Eisenthart-Rothe R, Muller-Gerbl M, Wiedemann E, Englmeier KH, Graichen H. Functional malcentering of the humeral head and asymmetric long-term stress on the glenoid: Potential reasons for glenoid loosening in total shoulder arthroplasty. J. Shoulder Elbow Surg. 2008;17:695-702.

46. Walch G, Badet R, Boulahia A, Khoury A. Morphologic study of the glenoid in primary glenohumeral osteoarthritis. J Arthroplasty. 1999;14:756-760.

47. Walch G, Boulahia A, Boileau P, Kempf JF. Primary glenohumeral osteoarthritis: clinical and radiographic classification. The Aequalis Group. Acta Orthop Belg. 1998;64(suppl 2):46-52.

48. Walch G, Moraga C, Young A, Castellanos-Rosas J. Results of anatomic nonconstrained prosthesis in primary osteoarthritis with biconcave glenoid. J Shoulder Elbow Surg. 2012;21:1526-1533.

49. Walch G, Young AA, Boileau P, Loew M, Gazielly D, Mole D. Patterns of loosening of polyethylene keeled glenoid components after shoulder arthroplasty for primary osteoarthritis: results of a multicenter study with more than five years of follow-up. $J$ Bone Joint Surg Am. 2012;94:145-150.

50. Wirth MA, Rockwood CA Jr. Complications of shoulder arthroplasty. Clin Orthop Relat Res. 1994;307:47-69.

51. Young A, Walch G, Boileau P, Favard L, Gohlke F, Loew M, Mole D. A multicentre study of the long-term results of using a flat-back polyethylene glenoid component in shoulder replacement for primary osteoarthritis. J Bone Joint Surg Br. 2011;93:210-216. 